\title{
Chiron's manufacturing misfortunes boost competitors
}

Chiron's ongoing problems in influenza vaccine production have raised serious questions about the Emeryville, California company's future ability to compete in this particular segment of the vaccine market. And with Basel-based Novartis's recent bid for the Chiron shares it doesn't already own, the future of one of biotech's oldest companies as an independent firm is in jeopardy. Meanwhile, competition in the vaccine sector is consolidating with GlaxoSmithKline's (GSK) bid on Canadian ID Biomedical.

To lose an entire year's output from a single plant may be understandable. To lose a full year's production from two is less so, particularly given the increased scrutiny the company has come under in the past 12 months. In July 2005, Chiron had to scrap all 12 million doses of Begrivac influenza vaccine scheduled to come out of its Marburg plant in Germany, because of product sterility problems. This follows the loss of its license to produce Fluvirin for the US market during the 2004-2005 flu season from its facility at Speke, near Liverpool, in the UK (Nat. Biotechnol. 22, 1487-1488 2004).

As a result, Chiron's recently and expensively acquired position as the world's second largest flu vaccine supplier is now under threat; particularly as rivals London-based GSK and Vancouver-based ID Biomedical, who are already ramping up output significantly, in Germany and in Canada, respectively, may now merge. That's following London-based GSK's proposal to acquire ID outright. Even with Chiron's US license recently reinstated by the US Food and Drug Administration (FDA), the pressure on Chiron may not abate.

Conceivably, Novartis's and GSK's moves would not have occurred had Chiron not lost output from Speke and from its plant in Germany. A spokeswoman for the Langenbased Paul Ehrlich Institute, the German federal body that has regulatory oversight of the area, says it expects the problems in Marburg to be resolved before the start of the next production campaign. "Begrivac is expected to be back on the market for the 2006-2007 flu season," says Susanne Stoecker.

Nonetheless, the lapse may be seen as further evidence "that their problems with controls are systemic," says Gordon Richman, vice president of compliance consulting and general counsel at EduQuest, of Hyattstown, Maryland. The wide-ranging nature of the problems the FDA identified at the Speke plant suggests that the underlying cause of Chiron's problems is cultural, Richman says. "They're not pinpointing one particular issue. They're pretty much all

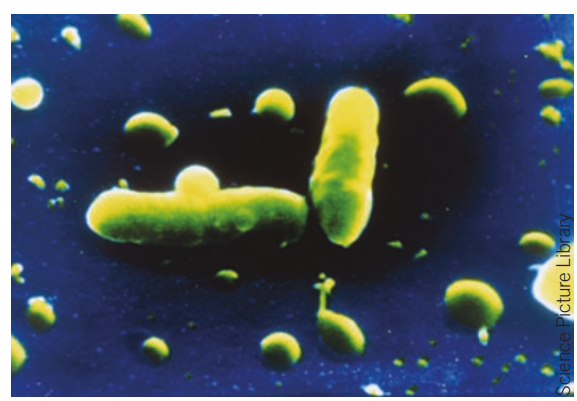

Serratia marcescens: the culprit in Chiron's flu vaccine production plant suspension in the UK.

over the place," he says. "The FDA's documents speak for themselves in that regard."

Chiron was just the third company to lose its manufacturing license in the UK since 2000, says Paul Hargreaves, technical manager at the London-based Medicines and Healthcare Products Regulatory Agency (MHRA), and the only one that was involved in vaccine production. Given the MHRA's regime of regular inspections, "licensing action resulting in suspension, variation or revocation is quite rare," says Hargreaves.

Although obviously necessary, passing regulatory inspections may not be sufficient to maintain standards. "Companies that usually get into trouble are relying on FDA inspections as an absolute barometer of their compliance," says Richman. Many of the problems at Speke actually predated Chiron's acquisition of the facility as part of its $\$ 890$-million cash purchase of UK biotech firm Powderject in July 2003 (Nat. Biotechnol. 21, 717, 2003). The plant had a rapid succession of owners, including GSK, Medeva, Celltech and then Powderject, and a checkered history with respect to FDA inspections. Since assuming control, however, Chiron failed to put the operation on a firmer footing, and ongoing problems continued to recur (see Box 1).

Trying to iron out such problems, while also trying to gear up for production for the following season, is extremely difficult. "It's like reen- gineering a train that's moving at one hundred miles an hour," Richman says. "Depending on how dysfunctional the train is, the complexity goes up by orders of magnitude."

Grappling with these issues, combined with the failure to maintain production at Marburg, has cost Chiron dearly in terms both of lost revenues and hard cash. The Fluvirin franchise alone was worth $\$ 219$ million in 2003. During the first half of 2005, Chiron spent \$66 million on plant remediation costs, legal expenses and what it referred to as "increased idle facility costs" associated with its UK operation. The failures at Marburg added \$15 million more in costs during the same period.

The company's vaccines franchise has historically operated at a lower margin than either its biopharmaceutical or its blood testing businesses. There are no signs, though, that it is willing to exit from the influenza business, despite the apparent shakiness of the underlying platform. "Chiron believes Fluvirin is a key strategic asset. It wants to have a presence in the US market for when its mammalian cell culture vaccine is commercialized," says Eric Schmidt at SG Cowen in New York.

The extent of that presence is under threat, however. With its US license reinstated, Chiron hopes to sell up to 26 million doses of Fluvirin in the US during the 2005-2006 flu season, barely more than half of what it sold in 2003-2004. Meanwhile, GSK, which is doubling capacity at its Dresden plant, hopes to sell up to 10 million doses of its Fluarix product in the US in the coming season, having obtained FDA approval under the latter's fast-track procedure.

Before the takeout bid by GSK, ID Biomedical had said it aimed to obtain approval for Fluviral in 2006 and to ship up to 25 million doses in the 2006-2007 season. Meanwhile Sanofi-Pasteur, the vaccines arms of Paris-based Sanofi-Aventis Group, which profited most from Chiron's absence from the market last year, has the capacity to produce up to 60 million doses in the upcoming season.

Cormac Sheridan, Dublin

\section{Box 1 Chiron's multiple biomanufacturing safety lapses}

Issues cropping up at the Speke biomanufacturing plant have been recurrent. For example, elevated 'bioburden' levels - excessive bacteria-in bulk batches of monovalent vaccine blended to create the trivalent, finished product were noted in FDA inspections going back to 1999. An FDA warning letter, issued to Chiron on 9 December 2004, noted that more than half of the monovalent blend pools used from March to October of that year exceeded the company's own bioburden alert level. That document also set out product contamination problems with Gram-negative bacterial species, "including but not limited to Serratia," as well as numerous breaches of standard operating procedures. 